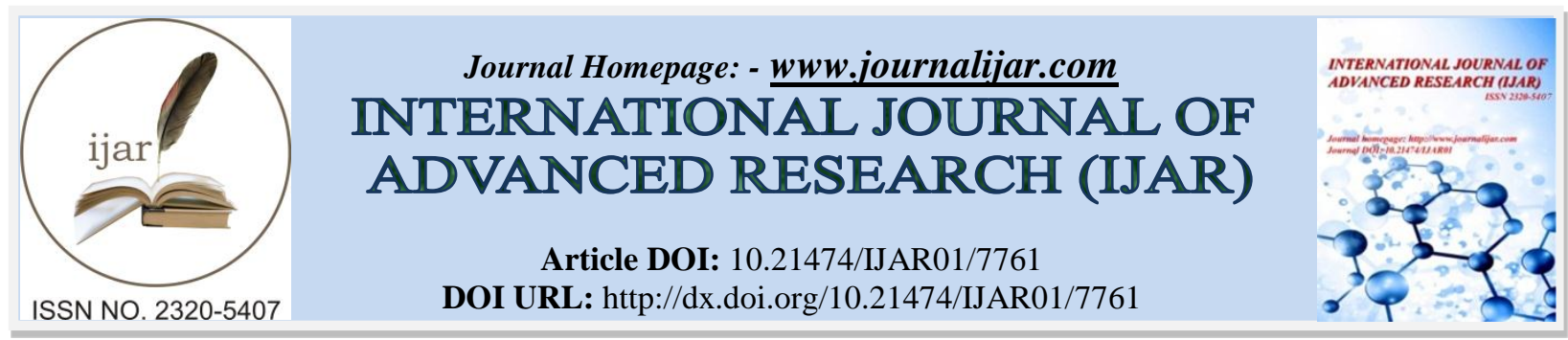

RESEARCH ARTICLE

\title{
A RARE NERVOUS TUMOR : THE MEDIASTINAL SCHWANNOMA (ABOUT ONE CASE).
}

\author{
Hasna Jabri, Loubna Najah, Wiam Elkhattabi and Hicham Afif. \\ Respiratory Diseases Department; Hospital 20 Août 1953; CHU Ibn Rochd Faculty of medicine of Casablanca \\ University Hassan II of Casablanca.
}

\section{Manuscript Info}

Manuscript History

Received: 25 July 2018

Final Accepted: 31 August 2018

Published: September 2018

\section{Abstract}

\section{Introduction:-}

Schwannoma is rare nervous tumors developed at the expense of the nervous girdles of myalinated nerves fibers. They can be discovered in a fortuitous way or be responsible for médiastinal syndrome by compression of the organs of neighborhood. These hurts put diagnostic difficulties due to their deep location and require in the majority of the cases an appeal to a diagnostic surgery.

\section{Case report:}

We report the case of a 58-year-old patient, without pathological histories or toxic habits. He presented badly right thoracic pains, radiating in paralateral breastbone with a dyspnea in the effort for 1 month. The clinical examination was normal. Having eliminated a cardiological urgency, a radiography of thorax objectified an opacity with hilar projection and over the right hilum of médiastinal look ( Figure1). The thoracic scanner showed a mass of tissular density sitting at the level of the posterior médiastin centered by hypodense zones of $51 \times 38 \times 27 \mathrm{~mm}$ (Figure2). For a better anatomical approach of the mass, the thoracic magnetic resonance imaging (MRI) objectified a heterogeneous process posterior médiastinal in a paralateral gutters arriving at the contact of the vertebral arc without a lysis of the born and without invasion of the spinal canal. He is for the contact of the downward aorta without invading it. This process is hétérosignal in T1 and T2 raising, in a hétèrogène way after injection of the gadoliminium( Figure 3 ). After meeting of multidisciplinary dialogue, the patient was operated. The right video-assisted thoracotomy surgery allowed the resection of a mass of $70 \times 35 \times 30 \mathrm{~mm} 36 \mathrm{~g}$ member the lung. suites operating comment were simple. The histological study revealed a tumour fusiform cells on encapsulated proliferation. These cells expressed in a intense way the protein S100 without expression of the actine develop the muscle of ribband and the CD34. The set was in favour of a thoracic schwannome. No complementary care was proposed except a simple supervision.

\section{Discussion:-}

Schwannoma is rare benign tumor of neurogenic origin developed at the expense of the nervous myélinated girdles. At the thoracic level, they represent approximately $75 \%$ of the tumors of the nervous envelopes and arise most of the time at young patient's from 20 to 50 years old with a feminine ascendancy [1]. They are located most of the time at the level of the intercostal nervous roots situated in laterovertebral gutters [2]. Their extension can be intrathecal by the spinal foramens in approximately $5 \%$ of the cases [3]. They show themselves frequently by intercostal and brachial neuralgias, as with our patient, but are most of the time of fortuitous discovery on simple 
standard thoracic radiography. Sometimes, the thoracic schwannoma develops from other nervous structures myélinated less of the médiastinum: phrenic nerve or vagus nerve. This schwannoma has an often late mode of revelation during a compression of an organ of neighborhood: stridor, atelectasis, cough either hémoptysies by infringement of the trachéo-bronchial axis, hémodynamics disturb by compression of the cardiac cavities or the big vessels, dysphagia by compression of the oesophagus, dysphonia in case of récurrentiel schwannoma or hiccup in case of phrenic schwannoma. The malignant forms are rarer, arising at patient's affected by neurofibromatose, or having undergone a médiastinal irradiation. The malignant transformation of a mild schwannome is a rare eventuality, arising in less than $2 \%$ of the cases [1,4]. The diagnosis is histological on surgical part, in front of the existence of cells of different Schwann of morphology and organization, classified according to Antoni in zone A where they appear in beams, in pits aligned in fence and in zone B of cystic aspect and myxoïde nature. There is often a calcified component and of cystic degeneration. The immunohistochemistry shows the dominating expression of the protein S100 [ 1 ] such is the case at our patient. The thoracic scanner is little specific in the positive diagnosis showing a heterogeneous tissular mass of mitigation identical to the scrawny muscles, sometimes containing visible calcifications. The heterogeneous aspect can be observed as well in the mild schwannoma that cunning this character turns out not discriminating [5].The thoracic MRI finds every its indication in this type of tumor and can show a hypo or an iso-intensity in level-headedness T1. The heterogeneous aspect of sequences T2 corresponds to the architecture different from zones A and B of Antoni [ 6 ]. The cystic zones of involution are the same visible in T2 [ 7 ]. The MRI can differentiate between schwannoma and neurofibroma with which the outskirts is marked by hyperintense zones in T2 corresponding to the degeneration peripheral myxoïde, what gives a suggestive image in target. The data of the TEP-scanner cannot differentiate between a mild and malignant schwannoma and has no big place in the diagnostic or therapeutic approach. The surgery, diagnostic and therapeutic, remains the current reference [8]. Suites are generally simple with a low rate of local relapse. For the neurogenic tumors of the médiastin, the type of de facto surgery still discusses and can consist, either in a classic thoracotomy, or in an video assisted mini-thoracotomy from which benefited our patient and for whom Cardillo G. and al. [9] showed, from a series of 57 patients, a superiority in terms of morbidity, operating time, post-operative pains and duration the operating suites.

\section{Conclusion:-}

All in all, the not lymph node tumors of the posterior médiastinum always have to be the object of a precise radiological study then a thoracic surgery with complete exeresis ,without preliminary biopsy, preferentially by video assisted minithoracotomy.

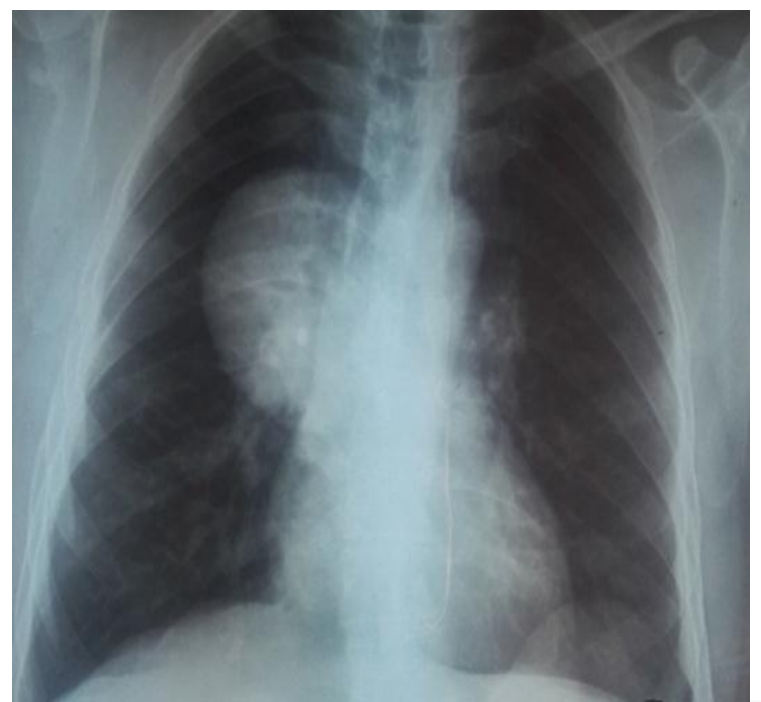

Figure 1:-Chest X-Ray: opacity with hilar projection and over the right hilum of médiastinal look 


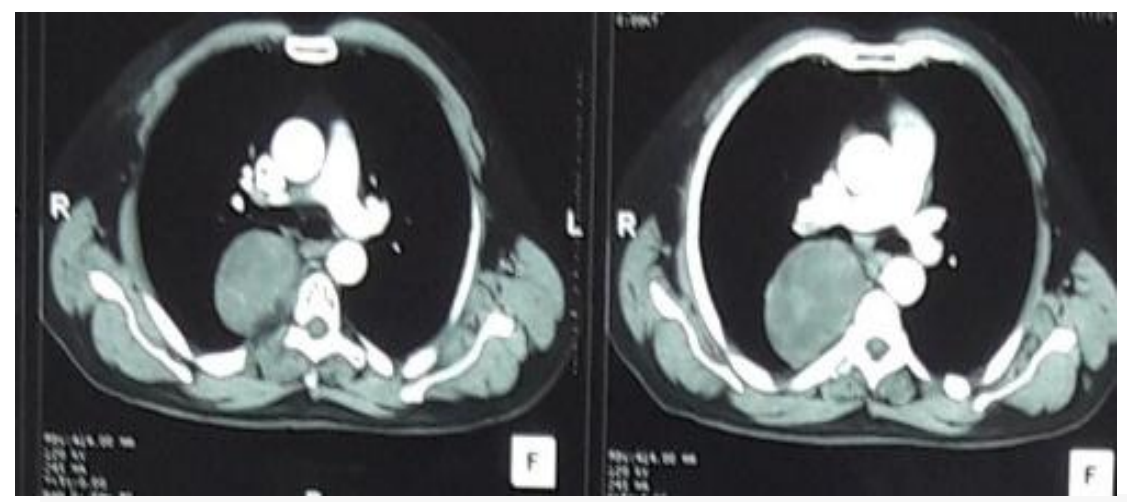

Figure 2: A thoracic scanner mass of tissular density sitting at the level of the posterior médiastinum

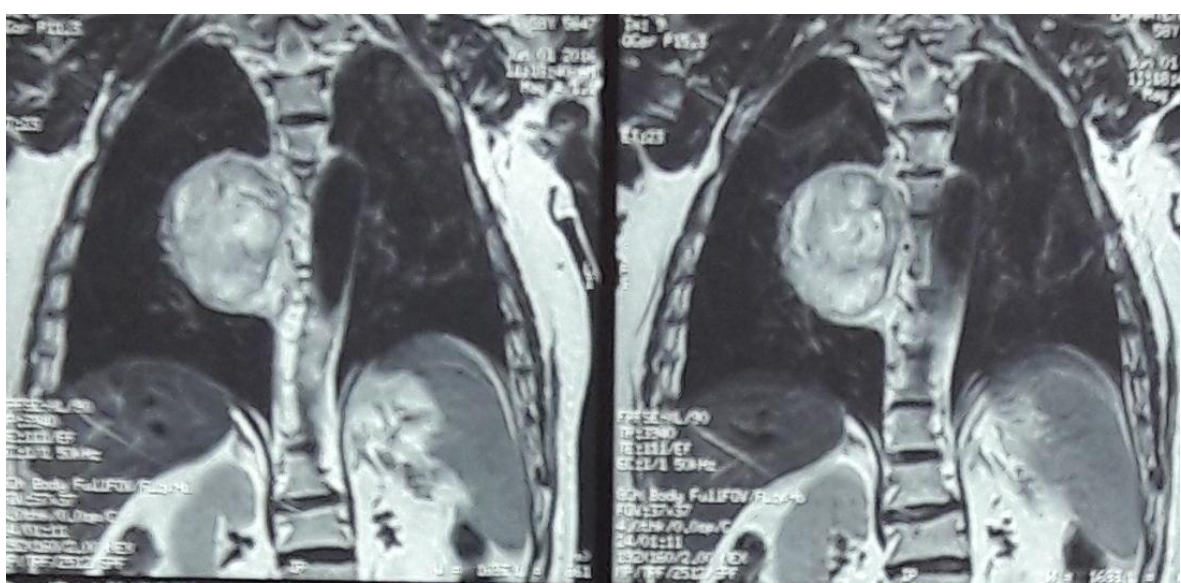

Figure 3:-Thoracic MRI heterogeneous process posterior médiastinal in a paralateral gutter in a hétèrogène way on $\mathrm{T} 2$

\section{Références:-}

1. Mordant P., Le Pimpec-Barthes F., Riquet M. Tumeurs nerveuses du médiastin de l'adulte. Rev Pneumol Clin $2010 ; 66: 81-94$.

2. Huang TW., Yang MH., Cheng YL., et al. Vagus nerve schwannoma in the middle mediastinum. Thorac Cardiovasc Surg 2010;58:309-16.

3. P.-A. Rogera, P. Bernab, G. Merluscab, J.-P. Jolyc, M.-A. Auquierd, H. Sevestree, C. Andrejaka, V. Jounieauxa. Schwannome médiastinal bénin du nerf vague : stratégies diagnostique et thérapeutique. Revue des Maladies Respiratoires (2012) 29, 70-73.

4. Fukai ., Masaoka A., Yamakawa Y., et al. Mediastinal malignant epithelioid schwannoma. Chest 1995; 108:574-5.

5. Cohen LM., Schwartz AM., Rockoff SD. Benign schwannomas: pathologic basis for CT inhomogeneities. AJR Am J Roentgenol 1986;147:141-3.

6. Sawas FA, Lababede O, Meziane MA, et al. A 54-year-old woman with incidentally discovered mass on a chest radiograph. Chest 2009;135:1673-8.

7. Sakai F, Sone S, Kiyono K, et al. Intrathoracic neurogenic tumors: MR-pathologic correlation. AJR Am J Roentgenol 1992;159:279-83.

8. Hoerbelt R, Keunecke L, Grimm H, et al. The value of a noninvasive diagnostic approach to mediastinal masses. Ann Thorac Surg 2003;75:1086-90.

9. Cardillo G, Carleo F, Khalil MW, et al. Surgical treatment of benign neurogenic tumours of the médiastinum: a single institution report. Eur J Cardiothorac Surg 2008; 34:1210-4. 